\title{
Influence of laboratory-related and endoscopy-related factors on the assessment of serum pepsinogens and gastrin-17
}

\author{
Elisabetta Goni ${ }^{a}$, Marino Venerito ${ }^{a}$, Christian Schulz ${ }^{\mathrm{a}, \mathrm{b}}$, Jochen Weigt ${ }^{\mathrm{a}}$, Cosima Langner ${ }^{\mathrm{a}}$, Alexander Link ${ }^{\mathrm{a}}$ and \\ Peter Malfertheiner ${ }^{a}$
}

Background and aim Serum pepsinogen I (PGI) and pepsinogen II (PGII) are noninvasive parameters in the detection of atrophic gastritis. The diagnostic add-on value of serum gastrin-17 (G-17) remains uncertain. The aim of this study was to assess the stability of these serum parameters over time and to evaluate the influence of clinical factors, such as upper gastrointestinal (GI) endoscopy and bowel cleansing, on serum PGI, PGIl, and G-17 assessment.

Patients and methods A prospective study was carried out in healthy individuals and patients. For the stability analyses, the plasma and serum samples from 23 individuals were processed at different time points with and without the addition of a stabilizer. Ten patients were included to evaluate the influence of upper GI endoscopy and 18 patients to evaluate the effect of bowel cleansing before colonoscopy.

Results PGI, PGIl, and G-17 levels were not statistically different in the serum and plasma. PGI and PGIl serum levels were stable over time. $\mathrm{G}-17$ is associated with time-dependent degradation $(P=0.0001)$. The addition of the $\mathrm{G}-17$ stabilizer showed no improvement in stability. Upper Gl endoscopy and bowel preparation before colonoscopy were associated with minimal variations in PGI and PGIl, whereas G-17 showed patient-specific alterations.

Conclusion PGI and PGIl serum levels are stable over time. However, G-17 stability is strongly dependent on the time of processing and storage; therefore, samples for $\mathrm{G}-17$ analysis need to be processed no later than $6 \mathrm{~h}$ after blood collection. Upper Gl endoscopy and colonoscopy preparation lead to minimal nonsignificant changes in basal PGI, PGIl, and G-17 levels. Eur J Gastroenterol Hepatol 29:1340-1345

Copyright @ 2017 Wolters Kluwer Health, Inc. All rights reserved.

\section{Introduction}

Serum pepsinogen I (PGI) and pepsinogen II (PGII) are proenzymes of pepsin, an endoproteinase of gastric juice, and they are related to the histologic and functional status of the gastric mucosa. PGI is secreted mainly by chief cells in the fundic mucosa, whereas PGII is also secreted by the pyloric glands and the proximal duodenal mucosa.

PGI and PGII are established noninvasive tools for the detection of severe chronic atrophic gastritis (CAG) [1,2]. This feature is characterized by hypoachloridria because of loss of appropriate gastric glands; therefore, there is a decrease in serum PGI, PGII, and PGI/PGII ratio [1-4].

It is still questioned whether the additional determination of gastrin-17 (G-17) would increase the diagnostic

\footnotetext{
European Journal of Gastroenterology \& Hepatology 2017, 29:1340-1345 Keywords: endoscopy-related factors, gastric biomarkers, gastrin-17, pepsinogens, preanalytical factors, serum stability of gastric biomarker

aDepartment of Gastroenterology, Hepatology and Infectious Diseases, Otto-von-Guericke University Hospital, Magdeburg and bepartment of Internal Medicine II, Hospital of the Ludwig Maximilians University of Munich, Campus Grosshadern, Munich, Germany

Correspondence to Peter Malfertheiner, MD, Department of Gastroenterology, Hepatology and Infectious Diseases, Otto-von-Guericke University Hospital, Leipziger Street 44, 39120 Magdeburg, Germany

Tel: + 49391671 3100; fax: + 493916713105 ;

e-mail: peter.malfertheiner@med.ovgu.de
}

Received 20 April 2017 Accepted 5 June 2017 accuracy. According to a recent meta-analysis on 894 patients and 1950 controls, G-17 is useful in the diagnosis of CAG and provides a better positive predictive value [5]. The serum test panel consisting of G-17, PGI, and Helicobacter pylori-IgG was shown to be in significant agreement with the endoscopic and histological findings in CAG [6]. The correlation of serum pepsinogens with histology was strengthened in a 12-year clinico-pathological follow-up study in which gastritis staging was performed along a scale of progressively severe atrophic gastritis, from the lowest (OLGA stage 0) to the highest (OLGA stage IV) and serology [7]. This led to the proposal of serum pepsinogens as risk assessment markers for gastric cancer [8-10]. However, a recent multicenter-blinded study discouraged the use of PGI, PGII, G-17, and H. pylori-IgG in the serological diagnosis of CAG [11]. The reasons for the discordant results were suggested to be as follows: (a) assessments of PGs and G-17 are influenced by intake of proton pump inhibitor, (b) different dynamics and values in plasma/serum levels if samples were collected either in the fasting or the postprandial state [12-14]. Therefore, it is crucial to document precisely the time points and under which conditions the blood samples are collected. Age and sex did not apparently seem to influence PGI, PGII, and G-17 assessment [15]. Serum and plasma are suitable biological samples for biomarkers [16]. However, in plasma or serum, biological molecules may be 
subject to proteolytic degradation caused by intrinsic peptidase activities [17].

The data on the possible influence of preanalytical factors as well as on endoscopy-related effects on the measurement of PGI, PGII, and G-17 in serum are lacking.

The aim of the present study was to test the stability of PGI, PGII, and G-17 over time and to evaluate the influence of endoscopy-related conditions on serum PGI, PGII, and G-17 assessment. The rationale was to check whether any chemical (41 bowel cleansing intake) and mechanical (e.g. biopsy sampling, endoscopy, gastric air insufflation) stimulations may lead to changes in serum concentrations of PGI, PGII, and G-17.

\section{Patients and methods}

\section{Ethical statement}

The study was approved by the local Ethics Committee (number 80/11). All investigations were performed at the Department of Gastroenterology, Hepatology and Infectious Diseases at Otto-von-Guericke University Magdeburg (Germany), in 2015. All study participants provided a written informed consent.

\section{Study design}

\section{Evaluation of stability}

The stability of serum biomarkers (PGI, PGII, and G-17) was evaluated in serum and plasma of 23 individuals: healthy individuals and patients undergoing upper gastrointestinal (GI) endoscopy for dyspeptic symptoms. All participants provided $20 \mathrm{ml}$ of peripheral blood samples divided into one plasma and three serum aliquots, $5 \mathrm{ml}$ each. Serum and plasma samples were centrifuged at different time points $\left(T_{0}=\right.$ within $30 \mathrm{~min}, T_{6}=6 \mathrm{~h}$, and $T_{24}=24 \mathrm{~h}$, overnight) following the sample collection, with and without the addition of a G-17 stabilizer (Biohit Oyj, Helsinki, Finland).

\section{Endoscopy-related factors}

Upper gastrointestinal endoscopy: In a second step, the influence of endoscopy-related factors on serum biomarkers was investigated. PGI, PGII, and G-17 were determined in blood samples obtained within $30 \mathrm{~min}$ before and $30 \mathrm{~min}$ $(5 \mathrm{ml}$ each) after the endoscopic procedure of patients requiring upper GI endoscopy for dyspeptic symptoms. Upper GI endoscopy was performed between 08.00 and $12.00 \mathrm{~h}$ in the morning, after an overnight fast, using Olympus (Olympus Europe, Hamburg, Germany) and Fujifilm (Fujifilm Europe, Düsseldorf, Germany) endoscopes. Sedation was performed either with Propofol and/or Midazolam according to the German Guidelines [18].

Bowel cleansing: To evaluate the impact of colonoscopy preparation on serum PGI, PGII, and G-17 values, we determined these biomarkers in blood samples of patients admitted in our department and undergoing colonoscopy for different indications. Blood samples were obtained after an overnight fast at two different time points, that is 1 day before and the day on which colonoscopy was scheduled before endoscopic investigation was performed. All patients underwent colonoscopy preparation with a solution containing Macrogol 3350, sodium sulfate, sodium bicarbonate, sodium chloride, and potassium chloride in split doses of 21 in the evening and 21 in the morning.

Assessment of pepsinogen I, pepsinogen II, and gastrin17 in serum and plasma: Blood samples were centrifuged $\left(2000 \mathrm{~g}\right.$ at $4^{\circ} \mathrm{C}$ for $10 \mathrm{~min}$ ) and stored at $-80^{\circ} \mathrm{C}$, with and without the addition of $25 \mu \mathrm{l}$ of a G-17 stabilizer (Biohit Oyj), at different time points ( $T_{0}=$ within $30 \mathrm{~min}, T_{6}=6 \mathrm{~h}$ and $T_{24}=24 \mathrm{~h}$, overnight) using an enzyme-linked immunosorbent assay (Biohit Oyj) according to manufacturers' instructions.

Statistical analysis: All statistical analyses were carried out using Graph Pad Prism Pro, version 6.0 (GraphPad Software Inc., La Jolla, California, USA). For groupwise comparison of parametrical data, we used Student's t-test and the Wilcoxon-test for comparison of two groups and Friedman's test for nonparametrical comparisons of three or more groups with Dunn's multiple comparisons posttest. For all tests, a two-sided $\mathrm{P}$ less than 0.05 was considered to be statistically significant.

\section{Results}

\section{Stability of pepsinogen I, pepsinogen II, and gastrin-17}

Overall, serum and plasma samples obtained from 23 individuals (male : female $=10: 13$; mean age \pm SD 53.3 \pm 19.4 ) were examined for the stability analysis of PGI, PGII, and $\mathrm{G}-17$.

Overall, PGI and PGII were stable over a period of $24 \mathrm{~h}$ (PGI mean values \pm SD: $T_{0} 166.9 \pm 114.1 \mu \mathrm{g} / \mathrm{l}, T_{6} 164.6 \pm 108.8$ $\mu \mathrm{g} / \mathrm{l}, T_{24}=166.6 \pm 113.3 \mu \mathrm{g} / \mathrm{l}$, Friedman's test $P>0.9$; PGII mean values \pm SD: $T_{0} 14.1 \pm 7.9 \mu \mathrm{g} / \mathrm{l}, T_{6} 14.3 \pm 8.2 \mu \mathrm{g} / \mathrm{l}, T_{24}$ $14.0 \pm 8.1 \mu \mathrm{g} /$, Friedman's test $P=0.8$ ), whereas serum values of G-17 showed a statistically significant decrease over time (G-17 mean values \pm SD: $T_{0} \quad 12.0 \pm 19.5 \mathrm{pmol} / \mathrm{h}, T_{6}$ $10.7 \pm 17.8 \mathrm{pmol} / \mathrm{l}, \quad T_{24} 8.2 \pm 14.8 \mathrm{pmol} / \mathrm{l}$, Friedman's test $P=0.0001)$. The relative decrease in the G-17 value was 20.9 and $60.7 \%$ at 6 and $24 \mathrm{~h}$ after blood collection, respectively (Fig. 1).

Furthermore, we evaluated the difference between serum and plasma samples. PGI, PGII, and G-17 levels were comparable between serum and plasma (PGI mean values \pm SD in serum vs. plasma: $191.5 \pm 163.4 \mu \mathrm{g} / \mathrm{l}$ vs. $192.7 \pm 163.9 \mu \mathrm{g} / \mathrm{l}$; Wilcoxon-test $P=0.6$; PGII mean values \pm SD: serum $33.4 \pm 58.5 \mu \mathrm{g} / \mathrm{l}$ vs. plasma $31.5 \pm 52.3 \mu \mathrm{g} / \mathrm{l}$; Wilcoxon-test $P=0.4$; G-17 mean values \pm SD: serum $25.1 \pm 36.1 \mathrm{pmol} / \mathrm{l}$ vs. plasma $25.1 \pm 37.3 \mathrm{pmol} / \mathrm{l}$; Wilcoxon-test $P=0.2$ ) (Table 1 and Fig. 2).

Finally, we evaluated whether the addition of a stabilizer or the time point of centrifugation may influence biomarker assessment. The use of the G-17 stabilizer has been proposed by the manufacturer to improve G-17 stability. The addition of the G-17 stabilizer had no effect on the serum and plasma stability of PGI and PGII (PGI Friedman's test $P=0.4$; PGII Friedman's test $P=0.1$ ). However, the addition of the G-17 stabilizer improved the G-17 stability in plasma (G-17 mean values \pm SD plasma without a stabilizer $25.0 \pm 37.3 \mathrm{pmol} / \mathrm{l}$ vs. plasma with a stabilizer $27.4 \pm 41.4$; Wilcoxon-test $P=0.007$ ), but not in serum (G-17 mean values \pm SD: serum without a stabilizer $25.1 \pm 36.1 \mathrm{pmol} / 1$ vs. serum with a stabilizer $26.5 \pm 38.7 \mathrm{pmol} / \mathrm{l}$; Wilcoxontest $P=0.5$ ) (Table 1 and Fig. 2). The G-17 stabilizer did not improve G-17 stability over time also in samples with 

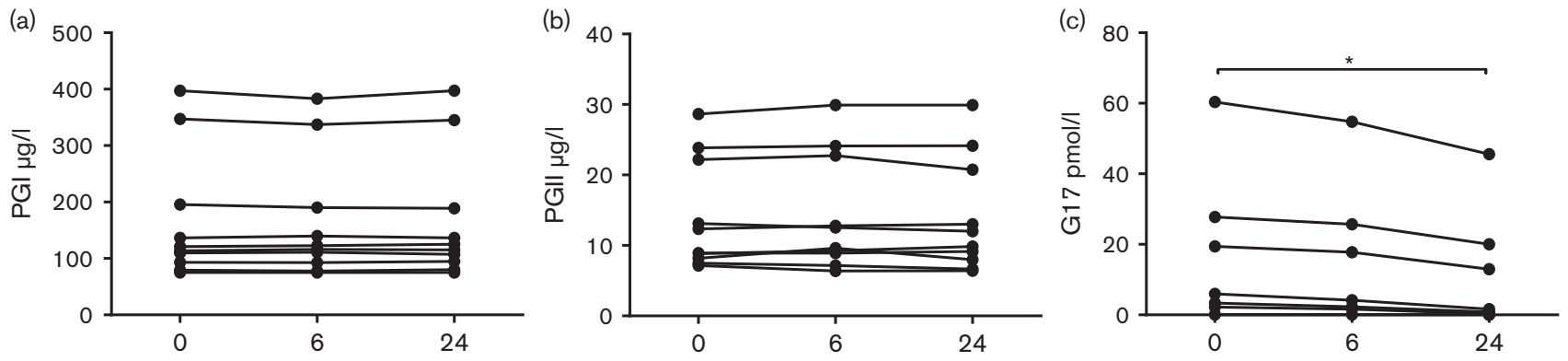

Fig. 1. The stability over time of serum PGI, PGIl, and G-17 levels. (a) PGI ( $\mu \mathrm{g} / \mathrm{l})$, (b) PGIl ( $\mu \mathrm{g} / \mathrm{l})$, and (c) G-17 (pmol/); $T_{0}=$ within $30 \mathrm{~min}, T_{6}=6 \mathrm{~h}, T_{24}=24 \mathrm{~h}$ (overnight). Friedman's test for nonparametrical comparisons of three or more groups with Dunn's multiple comparisons post-test. ${ }^{*} P<0.05$. G-17, gastrin-17; PGI, pepsinogen I; PGIl, pepsinogen II.

Table 1. Impact of stabilizer on the stability of pepsinogen I, PGIl, pepsinogen II, and gastrin-17 at $T_{0}$ (within 30 min from blood sample collection)

\begin{tabular}{|c|c|c|c|c|c|}
\hline & Serum (mean $\pm \mathrm{SD}$ ) & Serum + stabilizer $($ mean \pm SD) & Plasma (mean $\pm \mathrm{SD}$ ) & Plasma + stabilizer $($ mean \pm SD) & $P$ value* \\
\hline PGI $(\mu \mathrm{g} / \mathrm{l})$ & $191.5 \pm 163.4$ & $191.6 \pm 158.5$ & $192.7 \pm 163.9$ & $187.4 \pm 149.5$ & 0.4 \\
\hline PGII ( $\mu \mathrm{g} / \mathrm{l})$ & $33.4 \pm 58.5$ & $32.6 \pm 54.4$ & $31.5 \pm 52.3$ & $30.4 .4 \pm 50.3$ & 0.1 \\
\hline G-17 (pmol/l) & $25.1 \pm 36.1$ & $26.5 \pm 38.7$ & $25.1 \pm 37.3$ & $27.5 \pm 41.4$ & 0.03 \\
\hline
\end{tabular}

G-17, gastrin-17; PGI, pepsinogen I; PGII, pepsinogen II.

*Friedman's test for nonparametrical comparisons of three or more groups with Dunn's multiple comparisons post-test, $P<0.05$.
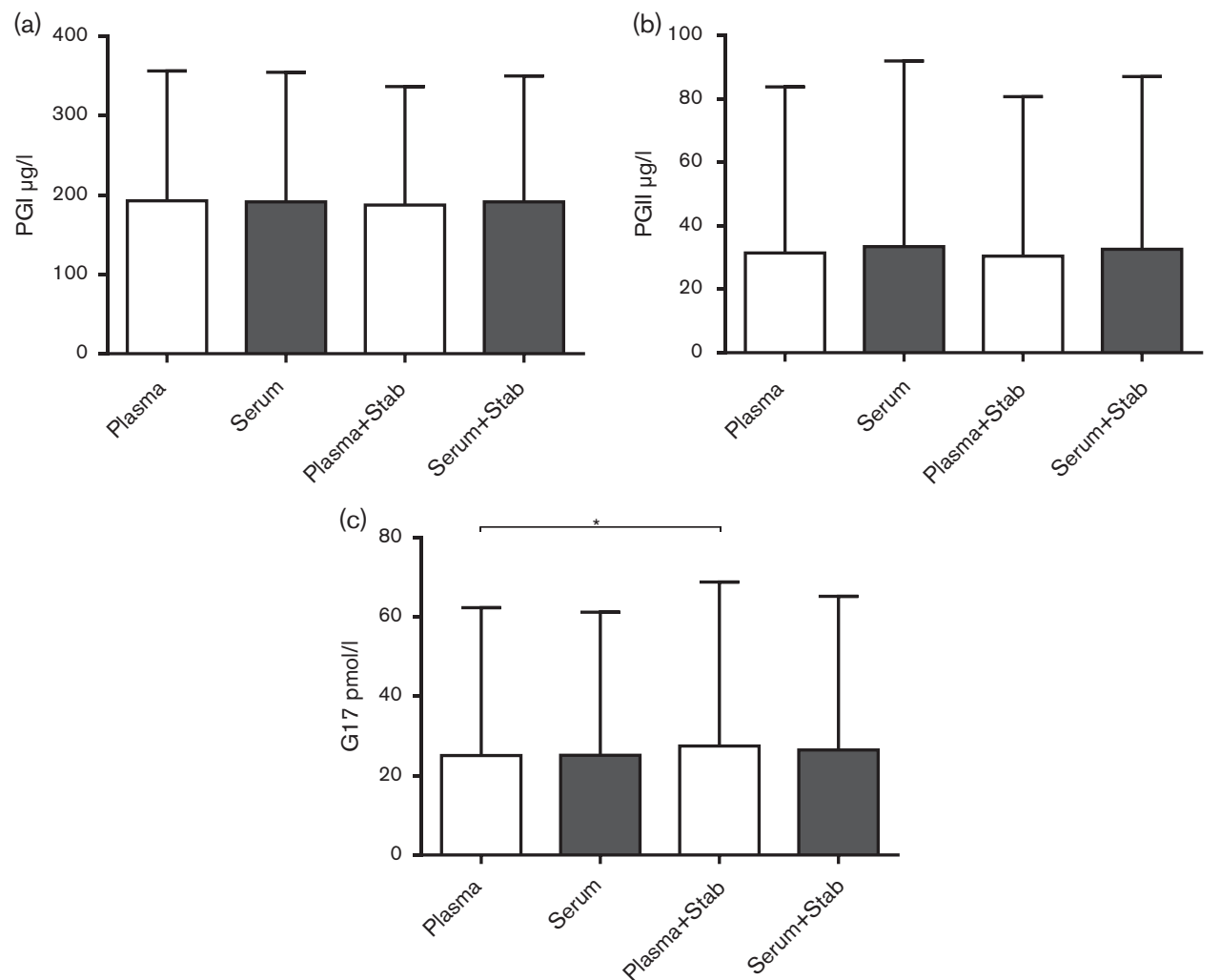

Fig. 2. Difference in PGI, PGIl, and G-17 levels between plasma and serum with and without a stabilizer. Assessment of plasma and serum for (a) PGI ( $\mu$ g/l), (b) PGIl $(\mu \mathrm{g} / \mathrm{l})$, and (c) G-17 (pmol/l) ( $\mu \mathrm{g} / \mathrm{l})$. Friedman's test for nonparametrical comparisons of three or more groups with Dunn's multiple comparisons posttest. ${ }^{*} P<0.05$. G-17, gastrin-17; PGI, pepsinogen I; PGIl, pepsinogen II.

immediate centrifugation (within 30 min after sample collection) and storage. Our results confirmed that G-17 assessment depends on the time of processing and storage. Indeed, G-17 levels were decreased by 20.9 and $60.7 \%$ in serum samples that were centrifuged and stored 6 and $24 \mathrm{~h}$ after blood collection, respectively, and this was independent of the addition of the stabilizer. For samples that were centrifuged immediately, but further stored at room temperature, the addition of the stabilizer was associated with improved stability (95.8 vs. $82.8 \%$ after $6 \mathrm{~h}$ and 78.9 vs. $54.0 \%$ after $24 \mathrm{~h}$ ) compared with samples without the G-17 stabilizer, respectively (Fig. 3). 

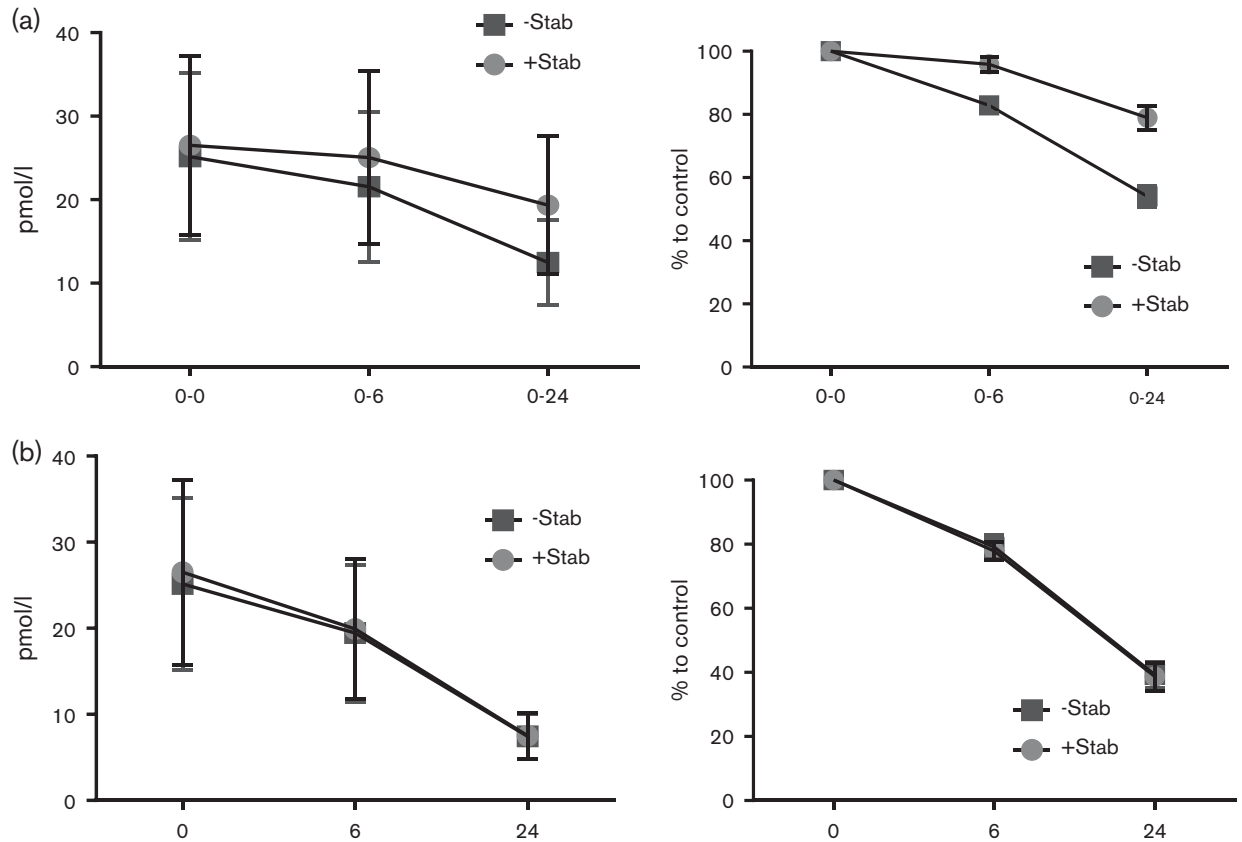

Fig. 3. The role of G-17 stabilizer addition before and after sample processing. (a) Centrifugation and storage, with or without the addition of a stabilizer immediately before sample processing; $T_{0}=$ within $30 \mathrm{~min}, T_{6}=6 \mathrm{~h}, T_{24}=24 \mathrm{~h}$ (overnight). (b) Addition of a stabilizer after sample processing and storage. $T_{0}=$ within $30 \mathrm{~min}, T_{6}=6 \mathrm{~h}, T_{24}=24 \mathrm{~h}$ (overnight). \%, Percentage of variation in G-17 serum levels; Stab, G-17 stabilizer.

Table 2. Influence of upper gastrointestinal endoscopy and bowel cleansing on PGl, pepsinogen I, pepsinogen II, gastrin-17 assessment

\begin{tabular}{|c|c|c|c|c|c|c|}
\hline & \multicolumn{3}{|c|}{ Upper Gl endoscopy $(N=10)$} & \multicolumn{3}{|c|}{ Bowel cleaning $(N=18)$} \\
\hline & Before $($ mean $\pm S D)$ & After (mean $\pm \mathrm{SD})$ & $P$ value* & Before (mean $\pm \mathrm{SD}$ ) & After (mean $\pm \mathrm{SD})$ & $P$ value* \\
\hline PGI $(\mu \mathrm{g} / \mathrm{l})$ & $213.6 \pm 118.8$ & $212.8 \pm 189.5$ & 0.16 & $154.6 \pm 83.0$ & $147.4 \pm 83.3$ & 0.9 \\
\hline PGII ( $\mu \mathrm{g} / \mathrm{l})$ & $40.3 \pm 65.9$ & $38.8 \pm 65.3$ & 0.1 & $10.9 \pm 6.0$ & $10.5 \pm 6.1$ & 0.9 \\
\hline G-17 (pmol/l) & $32.2 \pm 38.7$ & $29.8 \pm 34.0$ & $>0.99$ & $13.3 \pm 17.2$ & $16.6 \pm 14.9$ & 0.2 \\
\hline
\end{tabular}

G-17, gastrin-17; GI, gastrointestinal; PGI, pepsinogen I; PGII, pepsinogen II.

*Wilcoxon-test, $P<0.05$.

\section{Influence of endoscopy-related factors}

\section{Upper gastrointestinal endoscopy}

The influence of endoscopy-related factors on serum PGI, PGII, and G-17 was analyzed in the 10 patients undergoing upper GI endoscopy (male: female $=4: 6$, mean age \pm SD $58.3 \pm 19.4$ years)

Upper GI endoscopy did not influence serum PGI (mean values \pm SD: before $213.6 \pm 181.8 \mu \mathrm{g} / \mathrm{l}$ vs. after $212.8 \pm 189.5$ $\mu \mathrm{g} / \mathrm{l}$; Wilcoxon-test $P=0.16$ ), PGII (mean values \pm SD: before $40.3 \pm 65.8 \mu \mathrm{g} / \mathrm{l}$ vs. after $38.8 \pm 65.8 \mu \mathrm{g} / \mathrm{l}$; Wilcoxontest $P=0.1$ ), and $\mathrm{G}-17$ (mean values $\pm \mathrm{SD}$ : before $32.2 \pm 38.9 \mathrm{pmol} / \mathrm{l}$ vs. after $29.7 \pm 34.0 \mathrm{pmol} / \mathrm{l}$; Wilcoxon-test $P>0.99$ ) assessment (Table 2).

Overall, no changes were observed for PGI and PGII serum levels before and after upper GI endoscopy. However, considerable patients-specific variations in serum G-17 levels were observed with respect to endoscopic procedures. For instance, $30 \%$ of patients showed an increase and $30 \%$ showed a decrease in G-17 levels after upper GI endoscopy.

\section{Bowel preparation for colonoscopy}

Eighteen patients $(N=18$, male female $=14: 4$, mean age \pm SD: $66.6 \pm 13.3)$ undergoing colonoscopy were enrolled prospectively to assess the potential influence of bowel cleaning on the assessment of gastric biomarkers. Serum values of the analyzed biomarkers 1 day before and on the day on which colonoscopy was scheduled were as follows: PGI (mean values \pm SD: $154.6 \pm 83.0$ vs. $147.4 \pm 83.3 \mu \mathrm{g} / \mathrm{l}$; Wilcoxon-test $P=0.9$ ), PGII (mean values \pm SD: $10.9 \pm 6.0$ vs. $10.5 .4 \pm 6.1 \mu \mathrm{g} / \mathrm{l}$; Wilcoxon-test $P=0.9$ ), and G-17 (mean values \pm SD: $13.3 \pm 17.2$ vs. $16.6 \pm 14.8$ pmol/l; Wilcoxon-test $P=0.2$ ) (Table 2). Bowel preparation did not influence serum PGI and PGII values. With respect to serum G-17, individual variations between the two time points of blood collection were observed. In particular, serum G-17 values increased in four $(22.2 \%)$ patients, decreased in four $(22.2 \%)$ patients, and remained approximately the same in the remaining $10(55.5 \%)$ patients.

\section{Discussion}

Serum PGI and PGII are proposed as noninvasive biomarkers for the detection of gastric atrophy in clinical practice. There continue, however, to be uncertainties related to the methodology, the stability, and reproducibility of these parameters depending on the timing, sampling, and processing of samples. In this prospective study, we evaluated factors and 
conditions that might have an influence on the determination of these parameters. The main reason we tested serum PGI, PGII, and G-17 levels before and after upper GI endoscopy and in relation to bowel cleansing has been a practical one as blood for gastric 'screening' endoscopy-related procedures is often taken in the context of. The rationale was to check whether any chemical (4 lbowel cleansing intake) and mechanical (e.g. biopsy sampling, endoscopy, gastric air insufflation) stimulation might lead to changes in serum concentrations of PGI, PGII, and G-17.

\section{Stability over time of pepsinogen I, pepsinogen II, and gastrin-17}

The stability of the biomarker, reproducibility, and simplicity of the method are crucial factors for their determination and translation into the clinical practice [16]. Our results confirmed that PGI, PGII, and G-17 levels showed no differences in serum versus plasma assessment. Moreover, we showed that PGI and PGII levels are not influenced by preanalytical factors including storage time at different time points and centrifugation, and can therefore be considered as good biomarkers.

Recently, a study including 91 patients analyzed the value of PGI, PGII, and G-17 as noninvasive biomarkers in the diagnosis of atrophic gastritis [11]. In particular, G-17, according to the authors, did not provide any additional diagnostic value. One of the potential explanations may be related to the stability of G-17 in serum samples over time. Indeed, we show that G-17 serum and plasma levels undergo substantial degradation depending on the processing and storage of the samples. Compared with the samples processed immediately with the best possible time/ efficiency following blood collection, a serum level variation of $20.9 \%$ was observed when samples were processed and stored no later than $6 \mathrm{~h}$ after blood sampling. The variation in G-17 in serum reached up to $60.7 \%$ for samples centrifuged and stored within $24 \mathrm{~h}$ after blood collection independent of the addition of the stabilizer. Therefore, we suggest that in real-life settings, the sample processing should be documented and processed ideally within $30-60 \mathrm{~min}$. Although this time interval is usually not achievable in 'real-life' settings, the processing should be no later than within 6 h. G-17 degradation is one of the most important limitations of the biomarker in clinical practice. The addition of the G-17 stabilizer did not improve of G-17 stability over time also in samples subjected to immediate centrifugation (within 30 min after sample collection) and storage. The majority of previous studies available do not specify the time point of centrifugation, processing, and storage time after sample collection. Our findings suggest that time of sample collection and determination should be documented carefully and specified to obtain reliable results. As also the addition of a stabilizer to the serum sample was not effective in antagonizing G-17 degradation over time, the degradation dynamics would allow for normalization of the G-17 levels by a formula that considers time point of sampling and degradation in percentage per hour.

\section{The influence of gastrointestinal endoscopy}

Several investigations have reported on a positive association between $H$. pylori infection and increased risk for the development of colonic neoplasms [19-24]. This has led to the proposal of combining colorectal cancer screening with PGI, PGII, and G-17 assessment. Our study showed that upper GI endoscopy and bowel preparation did not influence serum PGI and PGII values. However, endoscopy procedures and bowel cleansing led to slight but not significant changes in G-17 levels, associated with an intraindividual variation in $30 \%$ of the patients. G-17 variations may be because of mechanical stimulation of the gastric mucosa resulting from bowel cleaning, or gastric air insufflation, $\mathrm{pH}$-changes, or even biopsy sampling during upper GI endoscopy. Therefore, because of variations in gastric serum parameters, especially G-17 following endoscopy or bowel cleansing preparation, we stress that blood sampling should be performed only during the fasting state before endoscopic or other interventional procedures on the stomach and the bowel.

\section{Conclusion}

PGI and PGII serum levels are stable over time and their assessment is not influenced by preanalytical factors such as time of centrifugation, storage, or addition of stabilizer. In contrast, G-17 stability was strongly dependent on time to processing and storage and addition of the G-17 stabilizer does not provide an additional benefit if the samples are frozen following centrifugation.

In future clinical studies, it is advised to take blood samples in the fasting state and not following endoscopic procedures and bowel cleansing. The timing of sample collection and determination should be registered and specified to provide reproducible results.

\section{Acknowledgements}

Conflicts of interest

There are no conflicts of interest.

\section{References}

1 Malfertheiner P, Megraud F, O'Morain CA, Gisbert JP, Kuipers EJ, Axon AT, et al. Management of Helicobacter pylori infection-the Maastricht V/Florence Consensus Report. Gut 2017; 66:6-30.

2 Sugano K, Tack J, Kuipers EJ, Graham DY, El-Omar EM, Miura S, et al. faculty members of Kyoto Global Consensus Conference. Kyoto global consensus report on Helicobacter pylori gastritis. Gut 2015; 64:1353-1367.

3 Miki K, Ichinose M, Ishikawa KB, Yahagi N, Matsushima M, Kakei N, et al. Clinical application of serum pepsinogen I and II levels for mass screening to detect gastric cancer. Jpn J Cancer Res 1993; 84: 1086-1090.

4 Sande N, Nikulin M, Nilsson I, Wadström T, Laxén F, Härkönen M, et al. Increased risk of developing atrophic gastritis in patients infected with CagA + Helicobacter pylori. Scand J Gastroenterol 2001; 36:928-933.

5 Wang X, Ling L, Li S, Qin G, Cui W, Li X, et al. The diagnostic value of gastrin-17 detection in atrophic gastritis: a meta-analysis. Medicine 2016; 95:e3599.

6 Väänänen $H$, Vauhkonen $M$, Helske $T$, Rasmussen $M$, TunturiHihnala $\mathrm{H}$, Koskenpato J, et al. Non-endoscopic diagnosis of atrophic gastritis with a blood test. correlation between gastric histology and serum levels of Gastrin-17 and Pepsinogen I. A Multicentre Study. Eur J Gastroenterol Hepatol 2003; 15:885-891.

7 Rugge M, de Boni M, Pennelli G, de Bona M, Giacomelli L, Fassan M, et al. Gastritis OLGA-staging and gastric cancer risk: a twelve-year clinico-pathological follow-up study. Aliment Pharmacol Ther 2010; 31:1104-1111.

8 Graham DY, Nurgalieva ZZ, El-Zimaity HM, Opekun AR, Campos A, Guerrero L, et al. Noninvasive versus histologic detection of gastric atrophy in a Hispanic population in North America. Clin Gastroenterol Hepatol 2006; 4:306-314. 
9 Vakil N, Moayyedi P, Fennerty MB, Talley NJ. Limited value of alarm features in the diagnosis of upper gastrointestinal malignancy: systematic review and meta-analysis. Gastroenterology 2006; 131:390-401.

10 Yanaoka K, Oka M, Yoshimura N, Mukoubayashi C, Enomoto S, Iguchi $\mathrm{M}$, et al. Risk of gastric cancer in asymptomatic, middle-aged Japanese subjects based on serum pepsinogen and Helicobacter pylori antibody levels. Int J Cancer 2008; 123:917-926.

11 McNicholl AG, Forné M, Barrio J, De la Coba C, González B, Rivera R, et al. Accuracy of GastroPanel for the diagnosis of atrophic gastritis. Eur J Gastroenterol Hepatol 2014; 26:941-948. (Erratum in: Eur J Gastroenterol Hepatol 2015; 27:113).

12 Agréus L, Storskrubb T, Aro P, Ronkainen J, Talley NJ, Sipponen P. Clinical use of proton-pump inhibitors but not H2-blockers or antacid/ alginates raises the serum levels of amidated gastrin-17, pepsinogen I and pepsinogen II in a random adult population. Scand J Gastroenterol 2009; 44:564-570.

13 Di Mario F, Ingegnoli A, Altavilla N, Cavallaro LG, Bertolini S, Merli R, et al. Influence of antisecretory treatment with proton pump inhibitors on serum pepsinogen I levels. Fundam Clin Pharmacol 2005; 19:497-501.

14 Xie GF, Drachenberg C, Yamada M, Wess J, Raufman JP. Cholinergic agonist-induced pepsinogen secretion from murine gastric chief cells is mediated by $\mathrm{M} 1$ and $\mathrm{M} 3$ muscarinic receptors. Am J Physiol Gastrointest Liver Physiol 2005; 289:G521-G529.

15 Nakamura K, Ogoshi K, Makuuchi H. Influence of aging, gastric mucosal atrophy and dietary habits on gastric secretion. Hepatogastroenterology 2006; 53:624-628.
16 WHO Library Cataloguing-in-Publication Data. Biomarkers in risk assessment: validity and validation. (Environmental health criteria; 222) Geneva 2001. Available at: http://www.inchem.org/documents/ehc/ ehc/ehc222.htm; 2001.

17 Chernecky CC, Berger BJ. Laboratory test and diagnostic procedures, 6th ed. Saunders, Philadelphia: Elsevier; 2012.

18 Riphaus A, Wehrmann T, Hausmann J, Weber B, von Delius S, Jung M, et al. Update S3-guideline 'Sedation for gastrointestinal endoscopy' 2014 (AWMF-register-no. 021/014). Z Gastroenterol 2016; 54:58-95.

19 Selgrad M, Bornschein J, Kandulski A, Hille C, Weigt J, Roessner A, et al. Helicobacter pylori but not gastrin is associated with the development of colonic neoplasms. Int J Cancer 2014; 135:1127-1131.

20 Shmuely H, Melzer E, Braverman M, Domniz N, Yahav J. Helicobacter pylori infection is associated with advanced colorectal neoplasia. Scand $J$ Gastroenterol 2014; 49:35-42.

21 Wu Q, Yang ZP, Xu P, Gao LC, Fan DM. Association between Helicobacter pylori infection and the risk of colorectal neoplasia: a systematic review and meta-analysis. Colorectal Dis 2013; 15:e352-e364.

22 Kim TJ, Kim ER, Chang DK, Kim YH, Baek SY, Kim K, et al. Helicobacter pylori infection is an independent risk factor of early and advanced colorectal neoplasm. Helicobacter 2017. [Epub ahead of print].

$23 \mathrm{Nam} J \mathrm{H}$, Hong CW, Kim BC, Kim YH, Baek SY, Kim K, Hong SN. Helicobacter pylori infection is an independent risk factor for colonic adenomatous neoplasms. Cancer Causes Control 2017; 28:107-115.

24 Sonnenberg A, Genta RM. Helicobacter pylori is a risk factor for colonic neoplasms. Am J Gastroenterol 2013; 108:208-15. 